\title{
A RESPONSABILIDADE CIVIL DO ESTADO POR DANOS AMBIENTAIS NOS CASOS DE OMISSÃO NA FISCALIZAÇÃO
}

\section{ARTIGO ORIGINAL}

NETO, Geraldo Miranda da Silva ${ }^{1}$

OLIVEIRA, Ana Paula Salviano ${ }^{2}$

PINTO, Gilberto de Andrade ${ }^{3}$

NETO, Geraldo Miranda da Silva. OLIVEIRA, Ana Paula Salviano. PINTO, Gilberto de Andrade. A responsabilidade civil do Estado por danos ambientais nos casos de omissão na fiscalização. Revista Científica Multidisciplinar Núcleo do Conhecimento. Ano 05, Ed. 05, Vol. 13, pp. 51-68. Maio de 2020. ISSN: 2448-0959, Link de acesso:

\section{RESUMO}

Estar e viver em um ambiente ecologicamente equilibrado é, entre outros, um direito fundamental previsto na Constituição Federal de 1988, sendo um dever do Estado e da coletividade preservar e prevenir o meio em que vivemos para as presentes e futuras gerações. A partir desse contexto, é possível notar a importância do tema, por se tratar de um direito essencial e indispensável ao ser humano e uma obrigação dos cidadãos e do Estado devendo atuar na prevenção e reparação nos danos ambientais. O presente artigo tem o objetivo de analisar no ordenamento jurídico a responsabilidade estatal nos recorrentes casos de danos ambientais, pois diversas vezes o poder público busca de eximir de qualquer responsabilidade, deixando toda a população desamparada. Assim, para o desenvolvimento do tema, foi de extrema importância explorar, analisar e fazer um intenso estudo de leis, doutrinas e

\footnotetext{
${ }^{1}$ Graduação em Direito.

${ }^{2}$ Graduação em Direito.

${ }^{3}$ Mestrado em Direito. Especialização em Direito Público. Graduação em Direito.
} 
jurisprudências acerca da responsabilidade civil do Estado por omissão na fiscalização dos crimes ambientais, fazendo, então, a utilização do método Dedutivo. Foi necessário entender e elaborar conceitos sobre o dano ambiental, compreender os princípios norteadores do Direito Ambiental, como também, estudos a respeito das duas espécies de responsabilidade civil: objetiva e subjetiva. Ademais, foi constatado que ambas as espécies são responsáveis pelos atos praticados e, caso algum deles cause algum prejuízo, cabe ao causador a obrigação de reparar. A partir de tal pressuposto, tem-se que a responsabilidade civil do Estado, nestes casos, é objetiva. Contudo, a partir do estudo feito, compreende-se que incumbe ao Estado o dever de fiscalizar e, resta claro que a omissão ou a não ação de forma suficiente a impedir um crime ambiental, cabe a Ele à responsabilização de sua ação ou omissão de forma objetiva, independente da prova de culpa ou do dolo, bastando apenas à ocorrência de tal dano e o nexo de causalidade.

Palavras-Chave: Responsabilidade civil objetiva, Direito Ambiental, dano ambiental, crime ambiental, omissão na fiscalização.

\section{INTRODUÇÃO}

A Constituição Federal de 1988 dispõe em seu art. 225 os direitos fundamentais relativos ao meio ambiente, sendo, entre eles, um dever que compete ao Poder Público e a coletividade defender e preservá-lo. Através de órgãos fiscalizadores municipais ou estaduais -, o Poder Público consegue preservar o meio ambiente para as presentes e futuras gerações, garantindo um meio ecologicamente equilibrado e assegurando a sociedade uma qualidade de vida sadia. Mas, quando há omissão de fiscalização por parte deste, causando algum dano ou crime ambiental, é correto afirmar que compete ao Poder Público a responsabilidade civil objetiva?

Para o desenvolvimento do tema, foi necessário explorar, analisar e fazer um intenso estudo de leis, doutrinas e jurisprudências acerca da responsabilidade civil do Estado por danos ambientais nos casos de omissão da fiscalização, com a compreensão sobre os princípios norteadores do Direito Ambiental no qual foi indispensável para a elaboração de conceitos e opiniões ao longo do tema. 
Contudo, compreendeu-se que incumbe ao Estado o dever de fiscalizar, sendo que a omissão ou a não ação de forma suficiente a impedir um crime ambiental, cabe a Ele à responsabilização de tal ato de forma objetiva, independente da prova de culpa ou do dolo, bastando apenas à ocorrência de tal dano e o nexo de causalidade.

\section{O DIREITO AMBIENTAL}

O Direito Ambiental é um ramo do direito bastante moderno, pois fazia parte do Direito Administrativo e a partir da vigência da Lei no 6938/1981 - que dispõe sobre a Política Nacional do Meio Ambiente - e, posteriormente, com a entrada em vigor da Constituição Federal de 1988, foi consolidada a sua autonomia. Ademais, é multidisciplinar, ou seja, aborda outras temáticas além do Direito, como a Biologia, a Engenharia, entre outras. Para Wellington Pacheco Barros

o direito ambiental é um ramo do direito público e este, segundo conceituação clássica, se constitui no conjunto de normas que organizam o poder soberano e a ordem política e, no ponto que interessa, regulam o funcionamento, as relações e os interesses do Estado entre os seus agentes e a coletividade (BARROS, 2008, p. 41).

O Direito do Ambiental visa proteger o meio ambiente e o homem, pois, não há vida onde não há um ambiente preservado com os mínimos recursos para viver. Sendo assim, é um ramo do Direito Público que buscar amenizar os problemas na relação entre o homem e meio ambiente.

\subsection{CONCEITO DE MEIO AMBIENTE}

O conceito de meio ambiente é bastante amplo e, por muitas vezes, muito discutido. A Lei no 6938, de 31 de agosto de 1981, que dispõe sobre a Política Nacional do Meio Ambiente, seus fins e mecanismos de formulação, dispõe, em seu art. $3^{\circ}$, I, o seguinte:

Art $3^{\circ}$ - Para os fins previstos nesta Lei, entende-se por: 
I - meio ambiente, o conjunto de condições, leis, influências e interações de ordem física, química e biológica, que permite, abriga e rege a vida em todas as suas formas.

Para o doutrinador Toshio Mukai, o meio ambiente é definido como "um conjunto de normas e institutos jurídicos pertencentes a vários ramos do Direito reunidos por sua função instrumental para a disciplina do comportamento humano em relação ao seu meio ambiente" (MUKAI, 2007, p. 10).

E, para Edis Milaré, é delimitado como "O complexo de princípios e normas coercitivas reguladoras das atividades humanas que, direta ou indiretamente, possam afetar a sanidade do ambiente em sua dimensão global, visando à sua sustentabilidade para as presentes e futuras gerações". (MILARÉ, 2011, p. 1062).

É notável a cautela que ambos dão a caracterização do conceito sobre o meio ambiente, visto que, por ser um direito primordial e tão pouco discutido, a vasta diminuição ou exterminação do meio ambiente acaba por extinguir todos os meios de vida até então conhecidos e, por consequência, as leis existentes em toda a dimensão global.

\subsection{PRINCIPAIS PRINCÍPIOS DO DIREITO AMBIENTAL}

Os princípios do Direito Ambiental são importantes norteadores em que se encontram a sustentação em casos de lacunas na aplicação das leis que tratam a seu respeito. Partindo desse pressuposto, os principais princípios são:

\subsubsection{PRINCÍPIO DA PRECAUÇÃO}

O Princípio da Precaução foi criado pela conferência da Organização das Nações Unidas - ONU - sobre o desenvolvimento e meio ambiente no Rio de Janeiro no ano de 1992, através do principio 15.

Princípio 15 - De modo a proteger o meio ambiente, o princípio da precaução deve ser amplamente observado pelos Estados, de acordo 
com suas capacidades. Quando houver ameaça de danos sérios ou irreversíveis, a ausência de absoluta certeza científica não deve ser utilizada como razão para postergar medidas eficazes e economicamente viáveis para prevenir a degradação ambiental.

Assim, temos que tal princípio está relacionado a proteção no meio em que vivemos e na segurança da integridade da vida humana, buscando um ato antecipado à ocorrência do dano ambiental, ou seja, é um risco incerto. Alguns doutrinadores apontam que este deve ser visto como um princípio antecessor ao da prevenção justamente pelo fato de que sua preocupação não é evitar o dano ambiental, e sim evitar qualquer risco de dano ao meio ambiente.

Ademais, há de se observar que tal princípio se encontra no art. 225, $1^{\circ}$, IV , da Constituição Federal e, concomitantemente, no art. 10, §1ํㅡㄹ da Lei ํㅡ 6.938/81, assegurando que a efetividade desse direito incumbe ao Poder Público em realizar alguns atos, tais como a exigibilidade de estudos prévios de impactos ambientais em atividades que poderão causar significativas degradações ao meio ambiente e licenciamentos ambientais, ambos com vasta publicidade.

Resta claro dizer que o princípio da precaução não é um ato discricionário do Poder Público, mas sim uma regra prevista em lei, em que é necessário ter um estudo prévio do impacto ambiental, a devida fiscalização e o licenciamento, não podendo o Estado se eximir desta obrigação.

\subsubsection{PRINCÍPIO DA PREVENÇÃO}

Diferente do princípio supramencionado, este decorre da constatação de algum risco, ou seja, é um risco certo e quando há elementos seguros para afirmar que determinada atividade é efetivamente perigosa. Em termos práticos, uma vez que saiba a prévia ocorrência de uma atividade que apresenta riscos de danos ao meio ambiente, esta não poderá ser desenvolvida, visto que a prevenção deste dano é mais vantajosa que a própria remediação, pelo fato de que, caso ocorra tal atividade de degradação, aquele ambiente não será mais o mesmo, perdendo suas características, 
estruturas e proveitos que possuía antes da efetivação da atividade que acabou por destruí-lo, não conseguindo, por fim, aquele ambiente voltar a ser ao que era, sendo impossível a reparação pelo dano causado. Assim, a partir destas evidências, é dever do Estado buscar as melhores formas para que o problema seja sanado.

Disposto no art. 225, VI, da Constituição Federal, é expresso no texto do caput, ficando claro que impõe à coletividade e ao Poder Público o dever de proteger e preservar o equilíbrio ecológico, para as presentes e futuras gerações.

Não se trata de ato discricionário do Poder Público por ser meramente uma obrigação, uma vez que tenha conhecimento que determinada atividade apresenta riscos de dano ao meio ambiente, a mesma não poderá ser desenvolvida, pois, caso ocorra qualquer dano ambiental, sua reparação é praticamente nula.

\subsubsection{PRINCÍPIO DA REPARAÇÃO INTEGRAL}

Esse princípio aponta que a degradação causada ao meio ambiente em caso de algum incidente, sua recuperação deve ser a mais ampla possível, em alguns casos, independente da condição financeira do causador, podendo superar seu poder aquisitivo. Conforme a Lei no 7.347/85, em seu art. 13, se não for possível a reparação, será devida indenização em dinheiro, revertida para um fundo de defesa.

Por sua vez, Álvaro Luiz Valery Mirra, magistrado em São Paulo, lecionou que tal princípio deve conduzir o ambiente e sua respectiva sociedade a situações em medidas equivalentes à de pessoas beneficiárias se o dano não tivesse ocorrido. Por isso,

A reparação integral do dano ao meio ambiente deve compreender não apenas o prejuízo causado ao bem ou recurso ambiental atingido, como também, na lição de Helita Barreira Custódio, toda a extensão dos danos produzidos em consequência do fato danoso, o que inclui os efeitos ecológicos e ambientais da agressão inicial a um bem ambiental corpóreo que estiverem no mesmo encadeamento causal, como, por 
exemplo, a destruição de espécimes, habitats, e ecossistemas interrelacionados com o meio afetado; os denominados danos interinos, vale dizer, as perdas de qualidade ambiental havidas no interregno entre a ocorrência do prejuízo e a efetiva recomposição do meio degradado; os danos futuros que se apresentarem como certos, os danos irreversíveis à qualidade ambiental e os danos morais coletivos resultantes da agressão a determinado bem ambiental. (MIRRA, 2002, p. 314, 315)

Por fim, tal reparação deve considerar todas as dimensões de degradação sofridas pelo meio ambiente, sendo atuais ou futuros, materiais e imateriais, não admitindo limitação à reparabilidade.

\section{O CRIME AMBIENTAL E A SUA RESPONSABILIZAÇÃO CIVIL NO ORDENAMENTO JURÍDICO}

Atualmente, nota-se uma vasta degradação ambiental - extinção de espécies animais e vegetais, mudanças climáticas, entre outros - para a satisfação de novas necessidades da sociedade se tratando de qualidade de vida. Com isso foi necessário, além de outros motivos em comum, que o Direito Penal agisse em face da criminalização das condutas "antiecológicas".

No âmbito penal, se tratando de tal matéria sobre a responsabilidade jurídica é utilizado o princípio da intervenção mínima, abordada como a ultima ratio, que orienta e limita o poder de incriminar do Estado, analisando sempre que, só será aplicado se as outras formas de sanções ou outros meios de controle social tornarem-se insuficientes, restando, então, a cominação da área penal.

Nesse sentido, o doutrinador Édis Milaré (2016, p. 293) aduz quesitos a respeito do enquadramento na esfera penal, sendo as seguintes:

Mesmo quando, no mundo dos fatos, houver indícios da ocorrência de uma determinada conduta, que o Direito Penal qualifica, a priori, como criminosa, o hermeneuta, à luz do princípio da intervenção mínima, 
deverá avaliar as circunstâncias do caso concreto e a efetiva periculosidade da situação que se the apresenta, antes de, com açodamento, pretender simplesmente enquadrá-la na letra fria da lei.

Desta forma deverá o hermeneuta considerar todas as circunstâncias do ato, visando outros meios corretivos, concretizando assim o princípio da intervenção mínima.

Também se observa, na Constituição Federal, o princípio da cooperação, que segundo Nogueira "Nossa constituição Federal delega ao poder público a tutela do meio ambiente, mas também a toda coletividade (caput, 225), portanto para nós o sentido de cooperação é dever de todos prevenir" (NOGUEIRA, 2007, p. 16).

Neste sentido, observado o princípio, nota-se que é dever do Estado e da coletividade a tutela do meio ambiente, resguardada esta obrigação em nossa carta magna, abrindo caminho para a responsabilização de quem descumpri-la.

\section{A RESPONSABILIDADE CIVIL}

O Estado possui prerrogativas em sua atuação em virtude da supremacia do interesse público perante os interesses privados, aplicando o princípio da isonomia, inerente ao ordenamento jurídico constitucional, quando decorrem fatos em que, para o benefício de uma sociedade, o Estado causa um dano lícito para um determinado particular ou um pequeno grupo de particulares, em que os mesmos serão indenizados como forma de promover tal benefício e, acirrar e reparar tal desigualdade causada pela atuação estatal. E, ocorre da mesma forma quando o Estado causa um dano ilícito a um particular, a um grupo de particulares ou a uma sociedade, gerando um dever de reparar os danos.

Ademais, atualmente, esse dever de reparação pelos danos causados pela Administração Pública é, portanto, pacífico, tanto no ordenamento jurídico brasileiro, como na doutrina e na jurisprudência. 


\subsection{CONCEITO}

A responsabilidade civil exprime a ideia de reparação, ou seja, quando o ente público causa algum dano a terceiros, é incumbido a ele a obrigação do ressarcimento por tal prejuízo causado.

Tal responsabilização é regulamentada pela Constituição Federal, conforme se observa o art. $37, \S 6^{\circ}$ :

Art. 37. A administração pública direta e indireta de qualquer dos Poderes da União, dos Estados, do Distrito Federal e dos Municípios obedecerá aos princípios de legalidade, impessoalidade, moralidade, publicidade e eficiência e, também, ao seguinte:

\section{(...)}

$\S 6^{\circ}$ As pessoas jurídicas de direito público e as de direito privado prestadoras de serviços públicos responderão pelos danos que seus agentes, nessa qualidade, causarem a terceiros, assegurado o direito de regresso contra o responsável nos casos de dolo ou culpa.

No mesmo sentido, o Código Civil, em seu art. 43, estabelece a configuração da responsabilização do ente público, in litteris:

Art. 43. As pessoas jurídicas de direito público interno são civilmente responsáveis por atos dos seus agentes que nessa qualidade causem danos a terceiros, ressalvado direito regressivo contra os causadores do dano, se houver, por parte destes, culpa ou dolo.

Partindo dessa premissa, a doutrinadora Maria Sylvia Zanella di Pietro aduz o seguinte: "A responsabilidade civil é de ordem patrimonial e decorre do artigo 186 do Código Civil, que consagra a regra, aceita universalmente, segundo a qual todo aquele que causa dano a outrem é obrigado a repará-Io" (DI PIETRO, 2010, p. 611). 
Portanto, ressalta-se que a responsabilidade civil do Estado em face a terceiros não se exclui, desde que, a mesma tenha ocorrido de forma culposa ou dolosa para o então dano causado.

\subsection{DA RESPONSABILIDADE CIVIL OBJETIVA}

A responsabilidade civil objetiva é uma espécie definida como a responsabilidade sem culpa, tendo o foco no dano causado e não na falha de determinado comportamento humano que levou ao então acontecimento. Em outros dizeres, tal responsabilidade dispensa a comprovação da culpa em relação ao fato danoso, incidindo em decorrência de fatos lícitos - ou mesmo ilícitos -, bastando que o interessado constate a relação causal entre o fato e o dano.

Em igual perspectiva, Carvalho Filho (2014, p. 572) aduz o seguinte:

A responsabilidade objetiva é um plus em relação à responsabilidade subjetiva e não deixa de subsistir em razão desta; além do mais, todos se sujeitam normalmente à responsabilidade subjetiva, porque essa é a regra do ordenamento jurídico. Por conseguinte, quando se diz que nas omissões o Estado responde somente por culpa, não se está dizendo que incide a responsabilidade subjetiva, mas apenas que se trata da responsabilização comum, ou seja, aquela fundada na culpa, não se admitindo então a responsabilização sem culpa.

Desta forma, considerando a responsabilidade civil, nota-se que se fosse adotado a responsabilidade subjetiva seria muito difícil provar a culpa do causador do dano. $\mathrm{Na}$ responsabilidade objetiva existem diversas teorias a seu respeito, dentre elas a teoria do risco.

Analisando tais teorias, Washington de Barros Monteiro, em seu modesto entendimento, enumerou-as, de forma mais autêntica e precisa, na sua respectiva compreensão, lecionando que: 
A responsabilização objetiva desenvolveu-se em várias teorias sendo a primeira delas a do risco integral. Esta diz que a obrigação de reparar o dano nascerá do exercício de qualquer atividade, desta forma, para tal teoria, o direito à indenização decorrerá da existência de um dano ligado a uma atividade. A segunda teoria é a do risco proveito, a qual determina que a pessoa que exercer uma atividade e que dela obtém proveito ou vantagem estará obrigada a reparar os danos decorrentes do exercício desta atividade. A terceira é a teoria dos atos normais e anormais, que leva em consideração a média praticada pela sociedade. A quarta teoria é a do risco criado, segundo a qual a obrigação de reparar o dano nascerá simplesmente do exercício da atividade ameaçadora de risco. (MONTEIRO, 2001, p. 510).

Sendo assim basta que o interessado comprove causalidade entre a atividade exercida e o dano causado, por mais que a atividade danosa seja de fato lícita, não sendo necessário a comprovação de culpa, criando assim a obrigação de indenizar todos aqueles que de certa forma foram afetados.

\subsection{DA OBRIGAÇÃO DE INDENIZAR}

Segundo Sergio Cavalieri Filho (2010, p. 3) "O código civil, no título que figura em cima do seu art. 927, categoriza o dever de indenizar como obrigação. Vale dizer, entre as modalidades de obrigação existentes (dar, fazer, não fazer), o código incluiu mais uma - a obrigação de indenizar".

Sendo assim, por se tratar de uma obrigação, não cabe ao agente simplesmente se eximir de sua responsabilidade, devendo ele arcar com as consequências, buscando colocar o lesado no estado em que se encontrava antes do fato danoso, ou então pelo menos diminuir os danos. 


\section{A RESPONSABILIDADE CIVIL DO ESTADO POR OMISSÃO NA FISCALIZAÇÃO}

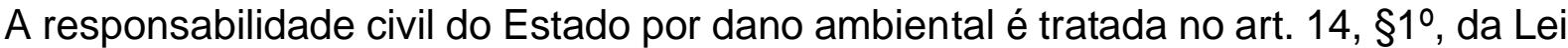
no 6.938/81, em que é classificada como responsabilidade civil objetiva. Tal lei é anterior a Constituição Federal de 1.988, porém foi recepcionada.

Sendo assim, o art. 225, em seu texto constitucional, estabeleceu e determinou que o Estado e sua respectiva coletividade tem diversos deveres, tais como de defender e preservar o meio ambiente, para que ambos possam viver em um ambiente ecologicamente equilibrado. Assim, o $\$ 1^{\circ}$ e seus respectivos incisos, impõem ao Poder Público e aos particulares o dever e poder em preservar o meio ambiente para as presentes e futuras gerações.

Resta claro que se tornou o instrumento mais eficaz na atuação reparatória, uma vez que o instituto tem como reconstituição da situação existente antes mesmo que haja a ocorrência de um possível dano ambiental.

A partir de tal premissa, Elenise Felzke Schonardie, dispõe sobre o seguinte entendimento:

Dessa maneira geral, a conduta omissiva leva ao dever de reparar, pois, nesses casos, a lei exige a realização de determinados atos, que devem ser observados pelo agente estatal. [...] A omissão, por exemplo, configura-se quando, no dever constitucional de proteger o meio ambiente (art. 225 da CF/88), o município mantém-se inerte. (SCHONARDIE, 2008, p.88).

Portanto é dever do Estado agir preventivamente, colocando em pratica seu Poder de Polícia, devendo ser penalizado em caso de omissão, exceto em casos fortuitos ou de força maior. 
Desta forma, qualquer ente estatal tem legitimidade para responsabilizar ou ser responsabilizado civilmente na condição de poluidor, não cabendo a eles se eximirem de tal responsabilidade.

\subsection{OS ATOS QUE CONFIGURAM A RESPONSABILIDADE CIVIL DO ESTADO}

De acordo com a Carta Magna, o reconhecimento da responsabilidade civil do estado só existe na presença de três elementos: evento danoso, ação (ou omissão) do estado e o nexo de causalidade.

a) O evento danoso, segundo a doutrina majoritária, é o resultado de uma soma de atividades que, de uma forma ou de outra, acabam por produzir a degradação do meio ambiente ou, então, de um ou mais de seus respectivos componentes.

Tal evento abrange as lesões materiais e imateriais, como dispõe o art. $1^{\circ}$, caput e inciso I, da Lei no 7347/85, com redação dada Lei $\mathrm{n}^{0}$ 12.529, de 2011, in verbis:

Art. 1ำ Regem-se pelas disposições desta Lei, sem prejuízo da ação popular, as ações de responsabilidade por danos morais e patrimoniais causados

I - ao meio-ambiente; (...)

Sendo assim, inexistindo o evento danoso inexiste a responsabilidade civil do estado. Neste contexto, o conceito de dano se dá no sentido amplo, não se restringindo apenas no dano material, ou então no dano moral, mais sim nos dois, levando em conta que o meio ambiente pertence a todos nós, e uma eventual tragédia pode causar lesões psicológicas e materiais.

b) A ação ou omissão do estado é a conduta adotada pelo estado perante certa situação, podendo ele agir ou simplesmente não agir. Esta conduta também pode ser lícita - nos conformes da legalidade e dos costumes ou ilícita - desrespeitando a legalidade e os costumes. Neste caso o que levamos em conta é a conduta que, ativa 
ou passivamente, contribui para que aconteça um evento danoso que afete um terceiro.

c) O nexo de causalidade é fundamental para o reconhecimento o da responsabilidade civil, pois poderá haver responsabilidade sem culpa, mas jamais poderá haver responsabilidade sem nexo de causalidade. Segundo Sergio Cavalieri Filho (2012, p. 67) "é o elemento referencial entre a conduta e o resultado. É através dele que podemos concluir quem foi o causador do dano." O nexo de causalidade é a ligação entre a ação ou omissão e o evento danoso, sendo assim, um elemento fundamental para a caracterização da responsabilidade civil.

\subsection{A RESPONSABILIDADE CIVIL DO ESTADO NOS DANOS E CRIMES AMBIENTAIS POR OMISSÃO NA FISCALIZAÇÃO}

A administração pública tem o poder-dever de resguardar o meio ambiente, através de seu poder de policia, respeitando desta forma as imposições trazidas pela Constituição Federal. E como já tratado, a cerca da responsabilidade civil, quem causa dano a outrem tem o dever de repara-lo. Desta forma o estado tem sim o dever se reparação nos casos de lesões ao meio ambiente, pois está incumbido a ele o dever de fiscalizar, de acordo com o artigo 225 da carta magna, não cabendo assim uma omissão completa do seu poder de policia.

Neste aspecto, poderá ocorrer a responsabilização do estado por duas formas, quando ele age diretamente causando o evento danoso, ou quando ele se omitir faltando com o dever de fiscalização. Para Cavalieri (2006, p. 201):

A chamada responsabilidade por fato de outrem - expressão originária da doutrina francesa - é responsabilidade por fato próprio omissivo, porquanto as pessoas que respondem a esse título terão sempre concorrido para o dano por falta de cuidado ou vigilância. Assim, não é muito próprio falar em fato de outrem. $O$ ato do autor material do dano é apenas a causa imediata, sendo a omissão daquele que tem o dever de guarda ou vigilância a causa mediata, que nem por isso deixa de ser 
causa eficiente. (...) Não se trata, em outras palavras, de responsabilidade por fato alheio, mas por fato próprio decorrente da violação do dever de vigilância. Por isso, alguns autores preferem falar em responsabilidade por infração dos deveres de vigilância, em lugar de responsabilidade pelo fato de outrem.

Nesse sentido, o estado tem o dever de tutelar o meio ambiente através da fiscalização para prevenir eventuais danos, não restando duvida da responsabilidade civil objetiva do mesmo.

Ademais, os tribunais têm o seguinte entendimento:

AÇÃO CIVIL PÚBLICA AMBIENTAL. DEGRADAÇÃO DE ZONA DE PRESERVAÇÃO ECOLÓGICA PELA INSTALAÇÃO E FUNCIONAMENTO CLANDESTINO DE FONTE DE POLUIÇÃO. INFRAÇÕES AMBIENTAIS REITERADAS DURANTE DÉCADAS. PROVA DO DANO. ALEGAÇÃO DE RESPONSABILIDADE OBJETIVA E SOLIDÁRIA DO MUNICÍPIO E DO ESTADO POR OMISSÃO NA FISCALIZAÇÃO. IMPOSIÇÃO DE OBRIGAÇÕES DE FAZER AOS ENTES PÚBLICOS E DE NÃO FAZER AO PARTICULAR. POSSIBILIDADE DE MULTA DIÁRIA POR DESCUMPRIMENTO E DE INVERSÃO DO ÔNUS DA PROVA. SENTENÇA QUE SE TORNOU INEXEQUÍVEL ANTE A FALTA DE RECURSO DO AUTOR. RECURSO OFICIAL, CONSIDERADO INTERPOSTO, E APELAÇÕES DO MUNICÍPIO E DO ESTADO PROVIDAS. APELAÇÃO DO RÉU PARCIALMENTE PROVIDA, APENAS PARA LIMITAR OS EFEITOS DA SENTENÇA À PARCELA DA PROPRIEDADE INSERIDA NOS LIMITES DA SERRA DO ITAPETI.(TJ-SP - APL: 90633578320098260000 SP 9063357- 83.2009.8.26.0000, Relator: Antonio Celso Aguilar Cortez, Data de Julgamento: 20/06/2013, 1a Câmara Reservada ao Meio Ambiente, Data de Publicação: 28/06/2013). 
A partir de então, é possível concluir que há, de fato, uma obrigação pré-existente do Estado de tutelar o meio ambiente, não restando dúvidas quanto a responsabilidade do ente estatal ser objetiva, em razão da omissão do Estado de forma ilícita ou por ter sido falho diante de tal situação, não impedindo, assim, a ocorrência dos danos ambientais.

\section{CONSIDERAÇÕES FINAIS}

A responsabilidade civil do Estado por omissão de fiscalização nos casos de danos ambientais abrange várias formas de defesa dos direitos do cidadão que são garantidas pela Constituição Federal de 1988, em que tem o intuito de possibilitar um número maior de ações/omissões que proporciona um considerável risco de potencial ofensivo ao meio ambiente, com a finalidade de garantir uma determinada preservação de um meio saudável para todos.

Apesar de pouco discutido, a matéria relacionada ao meio ambiente demonstra uma extrema importância para a sociedade, pois, uma vez que haja um grande descuido, acarretará um dano que irá se estender, mais cedo ou mais tarde, para o mundo inteiro. Por isso, a preocupação dos ambientalistas e ecologistas, pela permanente destruição do meio ambiente.

O direito fundamental do meio ambiente, assegurado pelo art. 225, da Constituição Federal, determina que o mesmo deve ser protegido e respeitado por todos, sendo das pessoas naturais até as jurídicas, ou também, por entes estatais, pois, tal direito tem como base a participação ativa do poder público e da sua coletividade.

A responsabilidade civil é um instituto criado para proteger e resguardar os direitos do homem. Logo, presume um dano, um prejuízo ao terceiro, e, com isso, o objetivo de reconstituir aquele equilíbrio que foi violado pelo dano, não bastando somente 0 ato da indenização, como também, ressarcir os prejuízos causados.

Por conseguinte, a responsabilidade civil do Estado por omissão configura quando este tinha o dever da ação e não o fez e, caso o tenha feito, agiu de forma 
inapropriada, devendo, portanto, deixar de praticar o ato para algum benefício de seus servidores. Com isso, esse dano gera algum prejuízo a uma pessoa ou um grupo de pessoas ou uma sociedade, devendo, assim, o Estado responder de forma objetiva, ou seja, independendo da prova de culpa ou do dolo, bastando apenas a ocorrência de tal dano e o nexo de causalidade. Nesse sentido, a responsabilidade do Estado diante da omissão em seu dever de fiscalizar é, sem dúvidas, objetiva, sendo necessária a aplicação dos princípios relativos ao meio ambiente, que são os da preservação, da precaução e da reparação, constituindo apenas uma finalidade, que seja garantido um meio ambiente saudável e equilibrado para as gerações atuais e futuras, cumprindo, assim, o texto Constitucional de que trata a respeito.

\section{REFERÊNCIAS}

BARROS, Wellington Pacheco. Curso de Direito Ambiental. $2^{\underline{a}}$ ed. São Paulo: Atlas, 2008.

BRASIL. constituição Da República Federativa Do Brasil De 1988. Disponível em: http://www.planalto.gov.br/ccivil_03/constituicao/constituicao.htm.

BRASIL. Lei oํ 10.406, de 10 de janeiro de 2002. Lei de Introdução às normas do Direito Brasileiro. Disponível em: http://www.planalto.gov.br/ccivil_03/leis/2002//10406.htm.

BRASIL. Lei no 6.938 , de 31 de agosto de 1.981. Política Nacional do Meio Ambiente. Disponível em: http://www.planalto.gov.br/ccivil_03/Leis/L6938.htm

BRASIL. Lei no 7.347, de 24 de julho de 1985. Ação civil pública de responsabilidade por danos causados ao meio-ambiente. Disponível em: http://www.planalto.gov.br/ccivil_03/leis/L7347orig.htm.

BRASIL. Lei no 9.605, de 12 de fevereiro de 1998. Lei de Introdução às normas do Direito Brasileiro. Disponível em: http://www.planalto.gov.br/ccivil_03/leis/19605.htm. 
CARVALHO FILHO, José dos Santos. Manual de Direito Administrativo. 26a ampl. E atual. Até 31-12-2012. São Paulo: Atlas, 2013.

CARVALHO, Matheus. Manual de Direito Administrativo. $3^{\text {a }}$ ed. Salvador: JusPODIVM, 2016.

CAVALIERI FILHO, Sergio. Programa de Responsabilidade Civil. 10ª ed. São Paulo: Atlas, 2012.

CAVALIERI FILHO, Sergio. Programa de Responsabilidade Civil. 4ª ed. São Paulo: Malheiros, 2006.

CAVALIERI FILHO, Sergio. Programa de Responsabilidade Civil. 9a ed. São Paulo: Atlas, 2010.

DI PIETRO, Maria Sylvia Zanella. Direito Administrativo. 23aㅗ ed. São Paulo: Forense, 2010.

GONÇALVES, Carlos Roberto. Direito Civil Esquematizado. 8aㅡ Ed. São Paulo, SP : Saraiva Educação, 2018.

MILARÉ, Edis. Direito do Ambiente: a gestão ambiental em foco. 7ª̣ ed. São Paulo: Revista dos Tribunais, 2011.

MILARÉ, Edis. Direito do Ambiente: a gestão ambiental em foco: doutrina, jurisprudência, glossário. 6aㅡ ed. rev. atual. eampl. São Paulo: Revista dos Tribunais, 2009.

MILARÉ, Édis. Reação jurídica a danosidade ambiental. Dissertação (Dissertação em direito) - PUC-SP. São Paulo, 2016.

MIRRA, Álvaro Luiz Valery. Ação civil pública e a reparação do dano ao meio ambiente. São Paulo: Juarez de Oliveira, 2002. 
MONTEIRO, Washington de Barros. Curso de direito civil. $2^{\underline{a}}$ ed. São Paulo: Saraiva, 2007.

MUKAI, Toshio. Direito Ambiental Sistematizado. 6 ed. São Paulo: Forense Universitária, 2007.

RIO DE JANEIRO. CONVENÇÃO SOBRE DIVERSIDADE BIOLÓGICA, 1992.

RODRIGUES, Marcelo Abelha. Direito Ambiental Esquematizado. 6를 Ed. São Paulo, SP : Saraiva Educação, 2019.

SCHONARDIE, Elenise Felzke. Dano ambiental: a omissão dos agentes públicos. Passo Fundo: UPF Editora, 2003.

SIRVINSKAS, Luís Paulo. Tutela Penal do Meio Ambiente. 4ª ed. São Paulo: Saraiva, 2011.

Enviado: Maio, 2020.

Aprovado: Maio, 2020. 